\title{
Editorial
}

\section{Surveying and diagnosing non-traditionally constructed houses in the United Kingdom}

\author{
Journal of Building Appraisal (2009) 4, 239-245. doi:10.1057/jba.2009.5
}

The stock activity of a building surveyor is the assessment of the condition of a subject building. Using knowledge of building technology, building pathology and environmental science, the surveyor uses skill and judgement to identify, diagnose the cause and propose remedial action for the building's defects. One of the factors that favours use of an experienced surveyor and supports the Royal Institution of Chartered Surveyors Assessment of Professional Competence system is the fact that defects sometimes do not result from the obvious, textbook causes. In this event, the surveyor needs to call upon experience and skill to avoid possibly litigious errors in diagnosis. However, in general terms, when all possibilities have been explored, the rules of building pathology do mostly apply to the traditionally built house, that is, damp areas discovered beneath $1 \mathrm{~m}$ above ground level are mainly the result of rising damp, and stepped cracking in masonry walls is most likely to result from substructure movement. The position can change somewhat when the house is not built using traditional construction methods or materials.

In the United Kingdom during the twentieth century, there have been a number of events that have created a large demand for extra housing, at the same time as there was a dearth of skilled construction workers. These times were mainly the years following the ends of the two world wars and also following the mass urban clearances of the 1960s. At each of these times, social housing providers turned to remotely manufactured components and houses, produced in factories that were then assembled on site, by often less skilled construction workers. A genre of these houses is that at a later date when tradesmen could be found they were often cladded in traditional materials to give the outward appearance of a traditionally built house. Nevertheless, the structural system remains non-traditional, as does the performance. Surprisingly, these houses were often more expensive to build and maintain than their traditional peers, so their adoption did not tend to extend beyond the normalisation of workforce levels. Additionally, they were built as strictly shorter term solutions with design lives of typically only 25-30 years.

The materials used to fabricate these buildings differ widely. They include in situ concrete, pre-cast concrete, timber, steel, aluminium and so on. Unfortunately also because of the dates of their construction, asbestos-containing materials were also commonly used. Given the peak periods when non-standard houses proliferated and the short design life afforded them, it would be reasonable to rank them as being almost extinct in the twenty-first century. However, many have greatly exceeded that original design life and are still occupied. Perhaps fortunately because of lender reluctance to offer mortgages on non-traditional houses, the number that left social landlord ownership and became owner-occupied is less than that of the traditionally built social housing stock, but some are privately owned and following cosmetic makeovers often with brick cladding 
and tiled roofs are ready to confuse the unwary surveyor undertaking a house purchase or similar survey.

A look at the list of the largest non-standard housing providers and their preferred methods of construction quickly shows that they vary greatly. Many manufacturers produced 1000s of units from widely differing materials and construction forms. The most prolific non-traditional builder George Wimpey, of the pre-cast concrete Wimpey No Fines house fame, produced a reputed 300000 non-traditionally built units over a 30-year period (Harrison et al, 2004). There are, however, a few general construction types which despite differing fixing methods and component designs dominate the non-traditional construction sector. The three types to be dealt within this editorial (and apologies to readers from areas where aluminium, timber or in situ concrete structures are found) are pre-cast concrete panel, steel and prefabricated housing. The intention is to look at the problems a surveyor might find while surveying or planning remediation activity in these types of domestic structures and to identify overall best practice procedures for identification and dealing with non-traditionally built houses in general.

Pre-cast concrete panel construction can utilise either large panels that are selfsupporting or smaller panels that fix between supporting concrete columns. The former also used in high rise construction resulted in the infamous Ronan Point collapse where a gas explosion dislodged one panel causing surrounding panels to fail in a domino action. One point in mitigation of defects found in most types of non-standard construction is that they are currently past their design life periods, so the fact that many concrete panels are suffering from typical concrete defects such as creep, concrete cancer, degradation of reinforcing, carbonation and panel distortion, is more a reflection of that fact than a detraction of the original design ideas. These problems are, however, exacerbated by the lack of replacement panels from now obsolete production lines.

Although concrete is a good and generally durable building material, it can be said that a concrete panelled house is only as strong as the condition of its fixing bolts. These, as was the case on the Clifton Social Housing Estate in Nottinghamshire, can be made of ferrous metals and susceptible to corrosion. This factor could, if the corrosion becomes acute, result in total failure of the structure and is exacerbated by common defects such as failed seals between panels that can allow moisture ingress. Further panel degradation responsible for moisture ingress can be caused by inadequate expansion gaps and weathering of the concrete. Part of the reason for use of this construction method was a lack of skilled builders meaning that the workforce responsible for erection of the panels was sometimes less experienced, resulting in inbuilt defects. Narrow wall dimensions make insulation difficult, and non-cavity construction can result in both damp and cold bridging, resulting in severe interstitial condensation, internal condensation and damp ingress. Again interstitial condensation is a possible cause of degradation of the panel fixing system. When brick or render cladding disguises the house's origins then the patterns of damp, particularly where flooring connects to the walling system, can be perplexing if viewed in terms of traditional housing defects, as can general areas of damp that appear not to conform to traditional damp migration patterns. Perhaps of greatest importance is the fact that ferrous fixing systems can make such houses unmortgageable, so not valuing a non-traditional concrete frame house as being a traditionally built structure would appear in surveying terms to be of greatest individual significance.

The following illustrations were taken recently from a substantial development of concrete panelled houses located in a prime residential position in the centre of a small urban town. Figure 1 shows the original construction form of small pre-cast concrete 


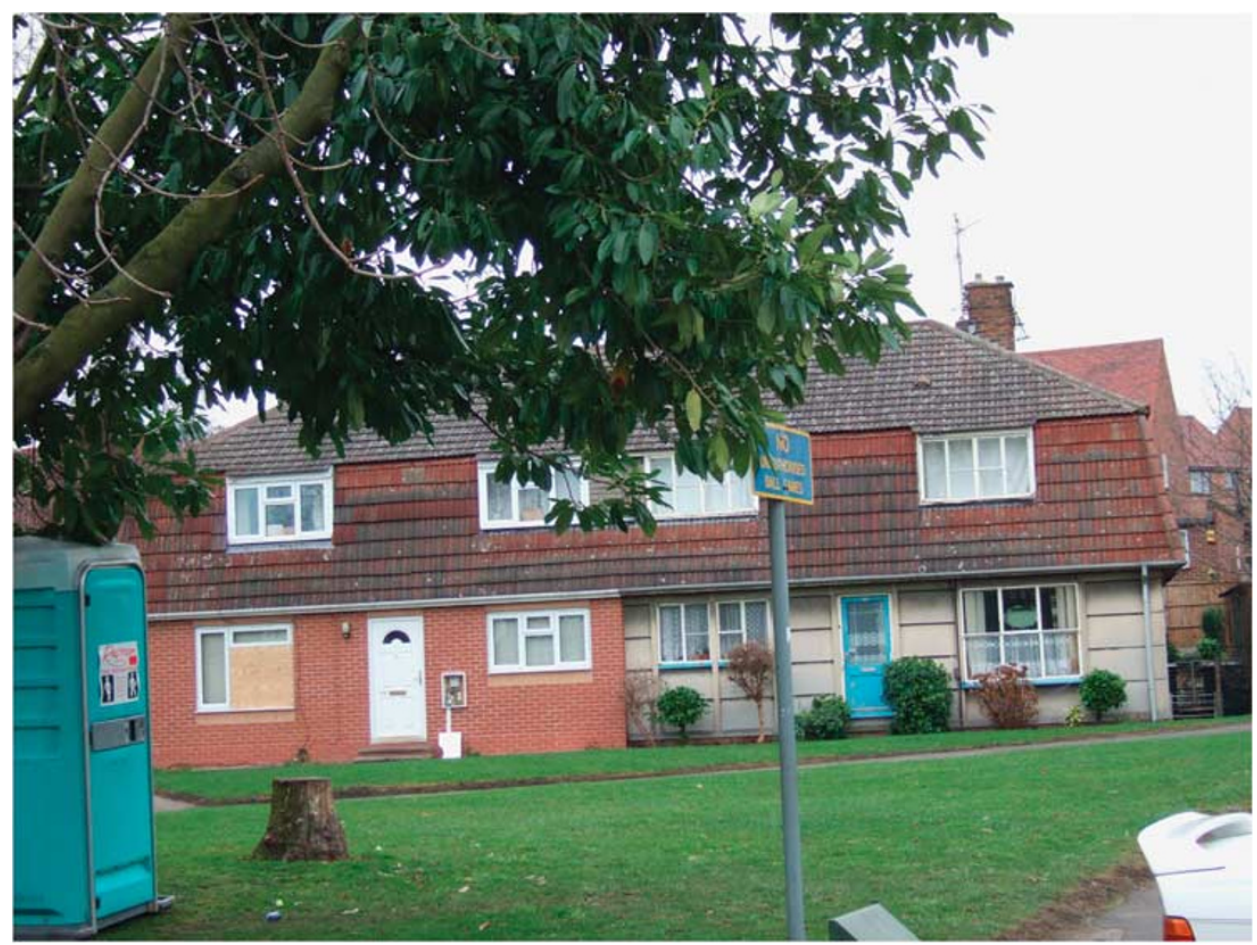

Figure 1: Original construction of small pre-cast concrete panels supported by pre-cast columns (right) and overcladded with brick (left).

panels supported by pre-cast columns, in the semi-detached house to the reader's right, whereas the left hand property has been overcladded with brick. Many of theses properties have become owner-occupied, and Figure 2 shows how once face-lifted with brick cladding and new UPVC fenestration they can be made aesthetically attractive. Figure 3 shows the different evolution of non-traditionally constructed semi-detached houses. The house left in its original form is now well past the original design life and consequentially the concrete panels, roof coverings and fenestration are all in extremely poor condition, and badly in need of exterior refurbishment.

Another type of non-traditionally built structure is the steel-framed and panelled house, such as the BISF and Trusteel systems. These structures were commonly retrospectively cladded in brick. The cladding, however, often causes its own problems as moisture trapped between closely fitting bricks and panelling causes the steel to corrode. Corrosion is a common problem in steel houses, particularly around the bases of structural columns. Interstitial moisture also corrodes wall ties and structural fixings. Steel is inherently a heat conductor not an insulator, and these structures often suffer from cold bridging and condensation. As with concrete panelled construction, the opportunity to insulate the walls is limited.

Steel-framed houses were built as lightweight structures and the retrofitting of tiled roof coverings to match the brick cladding can cause structural problems within a system designed to carry the loads of a much lighter roof covering. Corrosion of structural steel members and under-designing can also lead to distortion of the structure. Many of these houses with their brick cladded walls and renewed roof coverings would externally appear as traditionally built structures. Although they are not as susceptible as concrete panels to that Ronan Point-esk failure, their environmental performance and durability often fall 


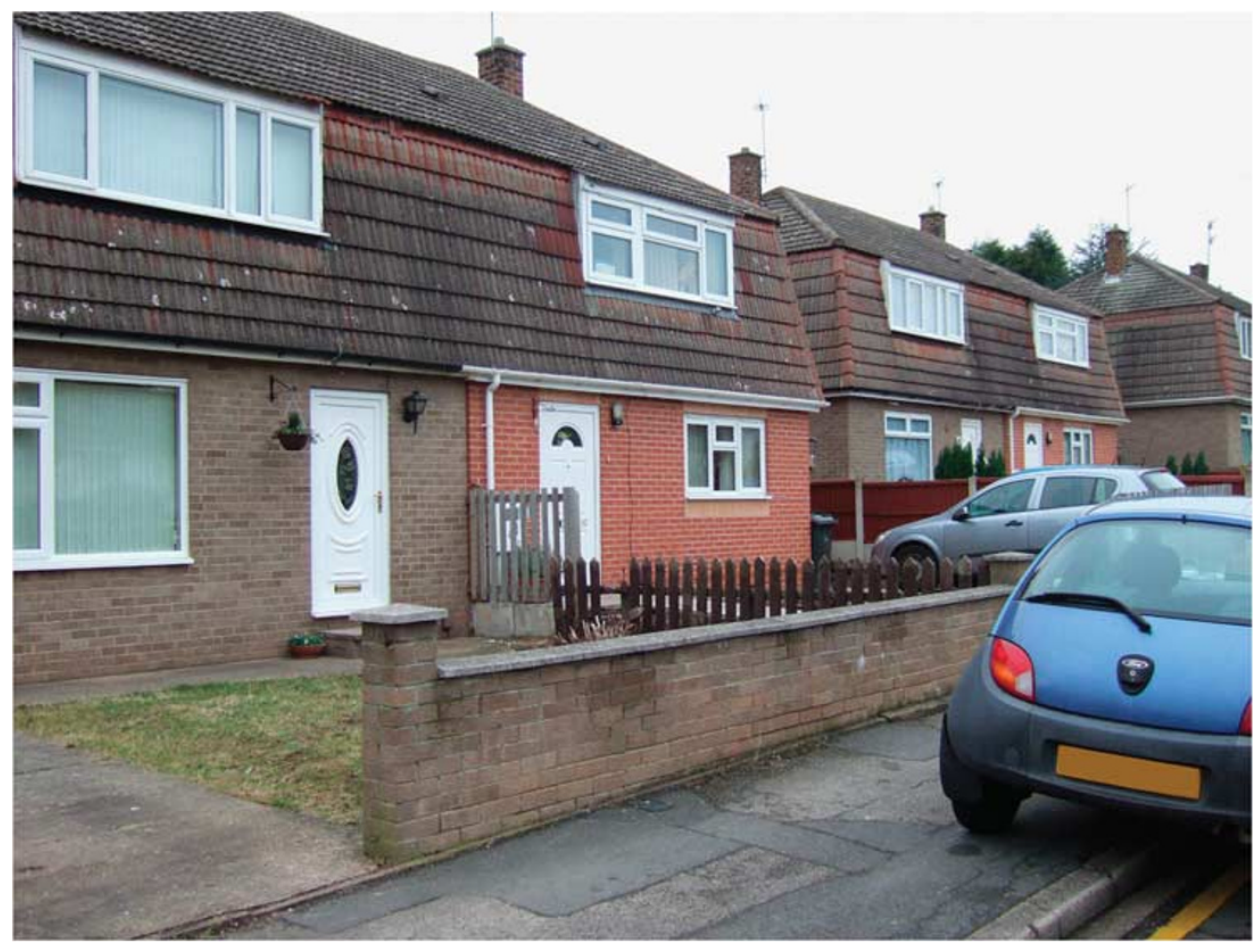

Figure 2: Once face-lifted with brick cladding and new UPVC fenestration, they can be made aesthetically attractive.

behind traditional builds, and miss-diagnosing one for the other could prove a costly mistake for both property purchaser and surveyor.

A final common form of non-standard housing is the prefabricated house such as the Unity system. Prefabricated houses were completely manufactured off site and arrived in situ in the form of a number of mostly finished units requiring only joining together on a concrete base or brick plinth, and connecting to the local services. An example of such houses would be the volumetric bungalows of the 1940s, which arrived on site in four pods, with all the water and drainage requiring services located in just one of the pods. These houses were usually given the lowest design life of any non-traditional structure; however, many still exist, and are now past double their maximum design life, even though the quality of materials and finishes chosen were never meant for such longevity.

As with the other two forms, these houses suffer from high levels of condensation, mostly because of badly designed ventilation, and the resultant degradation of structural members. Failure of seals and joints and age-related failure of external surfaces is also a common problem. These often result in further moisture ingress, and resultant additional damp problems. Unlike the other two featured forms, which often gave quite flexible accommodation, the internal space within prefabricated houses is often rigid and difficult to change. The factory-integrated services are difficult to change even though their obsolescence is common, which makes application of 'decent homes standard' upgrades problematical to instigate.

The main reference point to help a surveyor to deal with non-standard construction houses in the United Kingdom, once such a house is identified, is probably the BRE publication 'Non-traditional Houses - Identifying Non-traditional Houses in the 


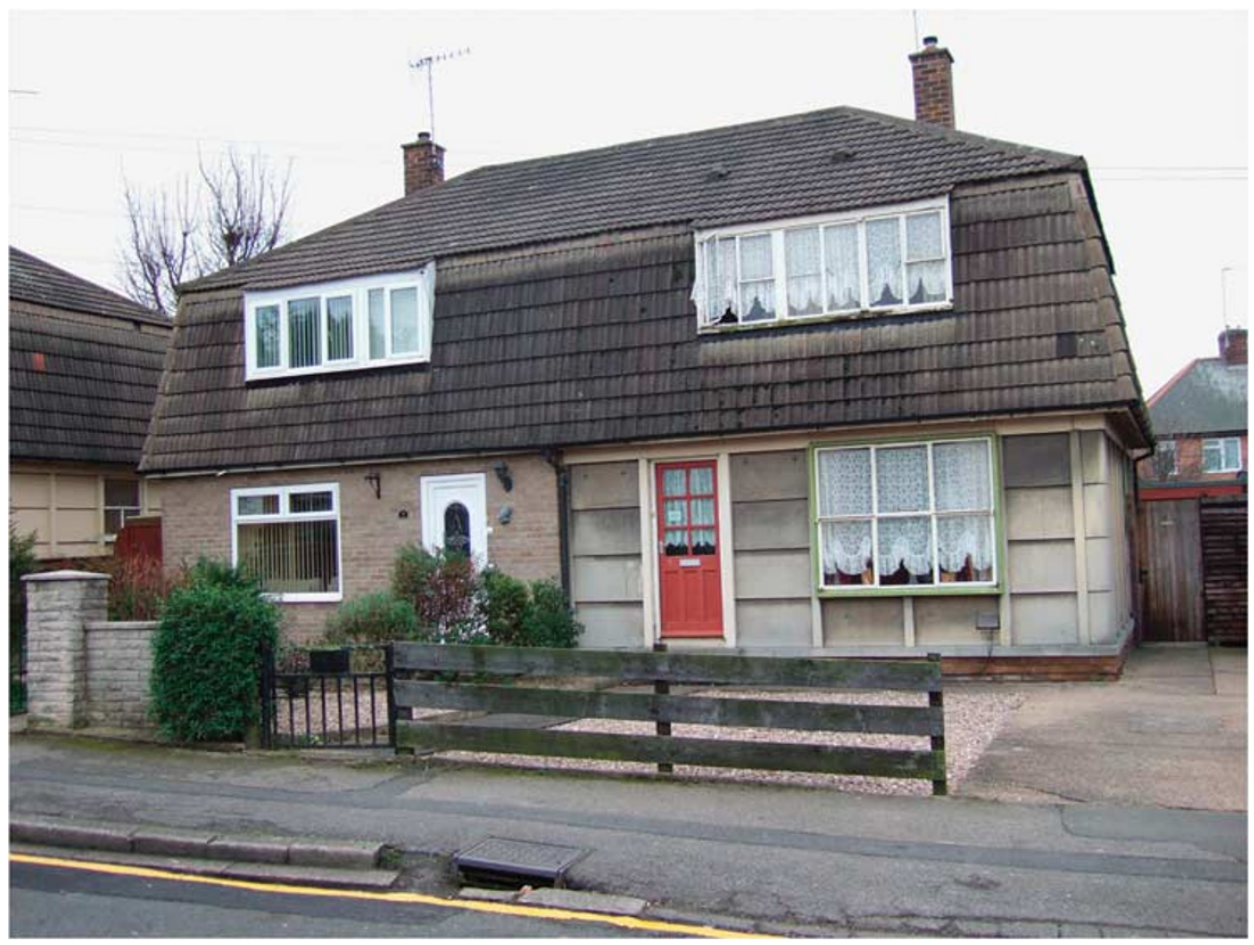

Figure 3: Different evolution of non-traditionally constructed semi-detached houses. The house still in its original form (right) requires significant refurbishment.

UK: 1918-75'. This work offers advice for dealing with non-traditional houses of all types and the girth of the volume pays testament to the vast numbers of different manufacturers who entered this market with their bespoke systems. The first piece of advice offered is to establish by means of the book and thorough survey, categorically, exactly what you are dealing with and what the basic construction form and materials used are.

Once that is established, a surveyor should accurately record the current condition of the structure, and as the original design life is almost certainly exceeded, project the current condition and defects forward to meet future revised design life periods. It is only after establishing these factors that any appropriate prognosis can be attempted.

If that prognosis includes continued occupation and alteration, the paramount consideration is that the structure is safe and will continue to be so. It must always be borne in mind that non-traditional housing has hidden structural form, and this is often only as sound as the condition or strength of its fixings. Imposition of extra loads by overcladding, and so on, should therefore be resisted, unless the structural robustness of the building is irrevocably proven. Finally as the materials used are not traditional care must be taken not to impose incompatible materials into the building, thus exacerbating any current problems, by sealing in damp, creating differential movement issues, and so on.

Perhaps the pivotal issue for the surveyor undertaking a survey of that quite plausible traditional looking brick and tiled house with new UPVC windows is whether it is in fact of traditional or non-traditional construction. In this respect, there is no substitute for local knowledge, within the practice office, and a thorough pre-inspection desk study 


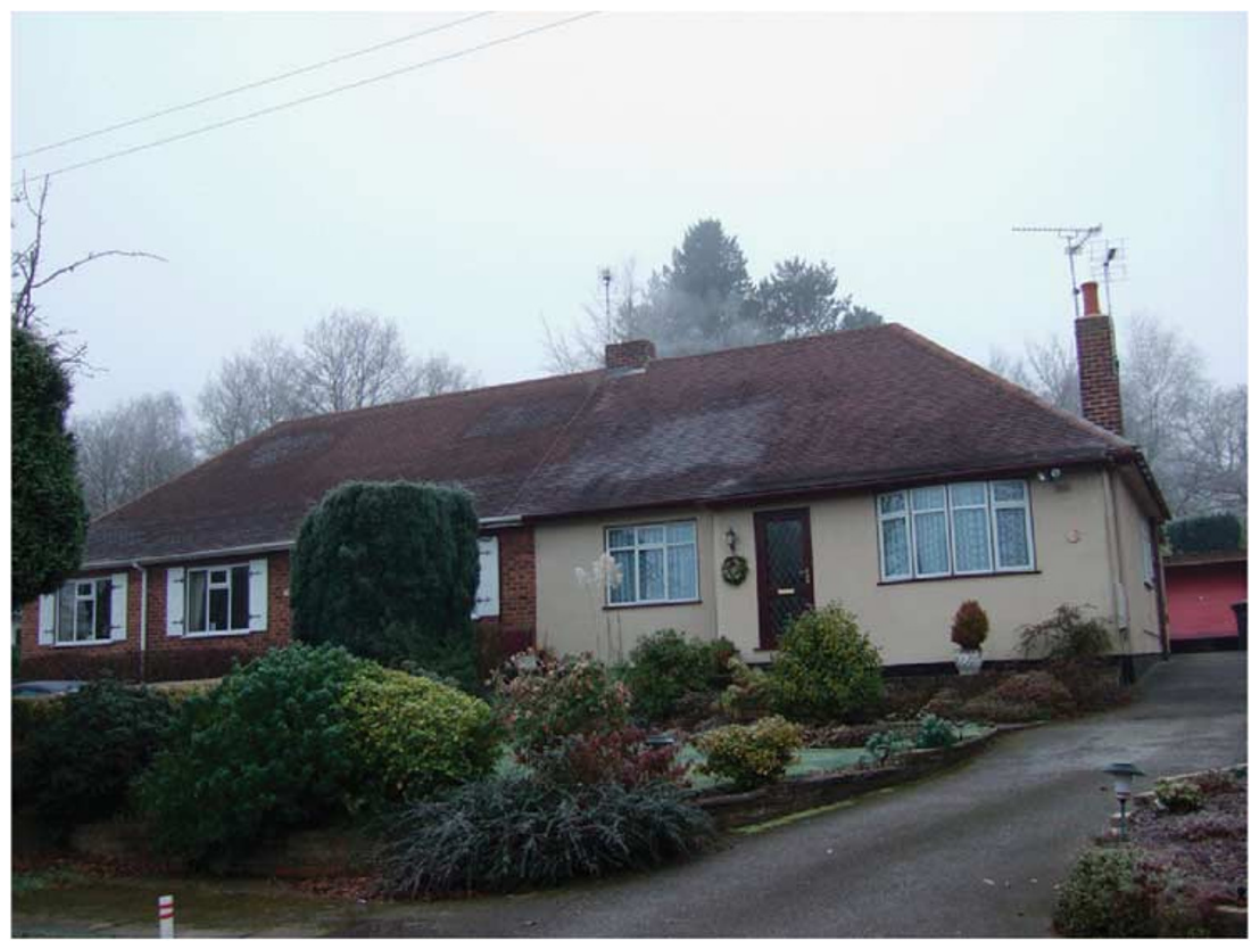

Figure 4: A pair of originally prefabricated semi-detached properties dating from the late 1950s which have evolved differently.

of pre-survey research. Another good method is to utilise information available from neighbours and others with local knowledge while on site. The hidden structure of an overcladded non-traditional house can often only be seen from the roof void, region when column heads, the inner-skin of cladded walls and possibly a non-timber truss roof structure can often be visible. The author chose a clearly non-traditional construction form to illustrate the required points; however, other forms are much less easy to spot. Another indicator of non-standard construction is the presence of defects that baffle the surveyor trying to apply them to traditional construction scenarios. The author's personal observations are that owner-occupied non-standard housing can often evolve independently of their peers. It is not unusual to see a row of non-traditional houses, each having a different cladding, different roof coverings or different fenestration.

Figure 4 represents a pair of originally prefabricated semi-detached properties, which formed part of a small development reputedly dating from the late 1950s. It can be seen how the two semi-detached properties have evolved differently; however, the main issue with these would be that the area has evolved around them and they are now located in one of the most prestigious and expensive residential areas of the county.

The fact is that non-traditionally built houses have entered the housing market, in spite of the fact that their original design lives should have rendered them extinct. These houses have unique construction forms, materials, inherent defects and common problems, when compared to traditional houses. These can include defects that could result in the failure of these houses, and ones that might render them inferior to living in a traditional house. Identification is essential to obtain the understanding required to accurately establish condition and devise an appropriate prognosis for the future. 
However, given the way that both mortgagers and home buyers perceive the durability and desirability of non-standards houses, it is essential that the surveyor should not confuse one for the other, as inappropriate diagnosis of defects and flawed technical advice might not be the worst outcomes of such confusion.

\section{REFERENCE}

Harrison, H., Mullin, S., Reeves, B. and Stevens, A. (2004) Non-traditional Houses - Identifying Non-traditional Houses in the UK: 1918-75. Bracknell: BRE Press.

Simon Mclean

Managing Editor 